\title{
Moving Bed Biofilm Reactor - A New Perspective in Wastewater Treatment
}

\author{
Borkar R.P ${ }^{1}$, Gulhane M.L ${ }^{2}$, and Kotangale A.J ${ }^{3}$ \\ ${ }^{I}$ The Principal, Government College of Engineering, Jalgaon \\ ${ }^{2}$ Associate Professor, Department of Civil Engineering, Government College of Engineering, Amravati, \\ Maharashtra, India, \\ ${ }^{3} P G$ Student, Department of Civil Engineering, Government College of Engineering, Amravati, Maharashtra, \\ India,
}

\begin{abstract}
A new advanced biological reactor for waste water treatment, Moving Bed Biofilm Reactor (MBBR) is discussed. General description of expected setup of reactor is given. The proposed results from different applications when used for domestic waste water will be discussed. Moving Bed technology presents several operational advantages, compared to other conventional biological treatments. Different applications of this technology for small plants will be studied, considering main investment and operating costs. Processes will take account of Moving Bed Biological Reactors (MBBR) with some sort of modifications. Conditions which may be studied will include COD removal, or COD and nutrients removal, with different primary treatments. Smaller biological reactor volumes and smaller secondary settling surface are needed. In conclusion, the results can indicate that MBBR with polyethylene media as Biofilm carrier may possess great potential to be used for OMs removal from water and wastewater. This study can be helpful to check possibility that the moving bed Biofilm process may be used as an ideal and efficient option for the total nutrient removal from municipal wastewater.

Index Terms: Waste water, Moving Bed, Biofilm, Bioreactor, Biofilm carriers, Hybrid processes, nutrient removal, sewage, Treatment
\end{abstract}

\section{INTRODUCTION}

Limited water resources and increasing urbanization require a more advanced technology to preserve water quality. One of the important factors affecting water quality is the enrichment of nutrients in water bodies. Wastewater with high levels of organic matter (COD) Phosphorus (P) and Nitrogen $(\mathrm{N})$ cause several problems, such as eutrophication, oxygen consumption and toxicity, when discharged to the environment. It is, therefore, necessary to remove these substances from wastewaters for reducing their harm to environments. Biological processes are a cost-effective and environmentally sound alternative to the chemical treatment of wastewater.

Biological processes based upon suspended biomass (i.e., Activated sludge processes) are effective for organic carbon and nutrient removal in municipal wastewater plants. But there are some problems of sludge settleability and the need of large reactors and settling tanks and biomass recycling. Biofilm processes have proved to be reliable for organic carbon and nutrients removal without some of the problems of activated sludge processes. Biofilm reactors are especially useful when slow growing organisms like nitrifiers have to be kept in a wastewater treatment process. Both nitrification and denitrification have been individually successful in the Biofilm reactor. There are already many different Biofilm systems in use, such as trickling filters, Rotating Biological Contactors (RBCs), fixed media submerged bio-filters, granular media bio-filters, fluidized bed reactors, etc. They all have advantages and disadvantages.

Due to the rapid urbanization, wastewater has been continuously and excessively released into the environment, causing significant impacts on human and wild life. Many organic compounds in municipal wastewater are detected in different types of wastewater, affecting water quality, human health and biodiversity in the ecosystems. These compounds have significant impacts on receiving water bodies so as finding an appropriate treatment technology to effectively remove organic matters $(\mathrm{OMs})$ in wastewater is very essential.

Two technologies are commonly used for biological treatment of sewage: activated sludge and trickling filters. A moving bed biological reactor (MBBR) is a compilation of these two technologies. The biomass in the MBBR exists in two forms: suspended flocks and a biofilm attached to carriers. It can be operated at high organic loads and it is less sensitive to hydraulic overloading.

The MBBR was developed in Norway at the Norwegian University of Science and Technology in co-operation with a Norwegian company Kaldnes Miljóteknologi (now Anox Kaldnes AS). The first MBBR was installed in 1989. Although it is a relatively new technology to the United States (first introduced in 1995), there are now over 400 installations worldwide in both the municipal and industrial sectors with over 36 in North America. 
The Moving Bed Biofilm Reactor (MBBR) is a highly effective biological treatment process that was developed on the basis of conventional activated sludge process and bio-filter process. It is a completely mixed and continuously operated Biofilm reactor, where the biomass is grown on small carrier elements that have a little lighter density than water and are kept in movement along with a water stream inside the reactor. The movement inside a reactor can be caused by aeration in an aerobic reactor and by a mechanical stirrer in an anaerobic or anoxic reactor.

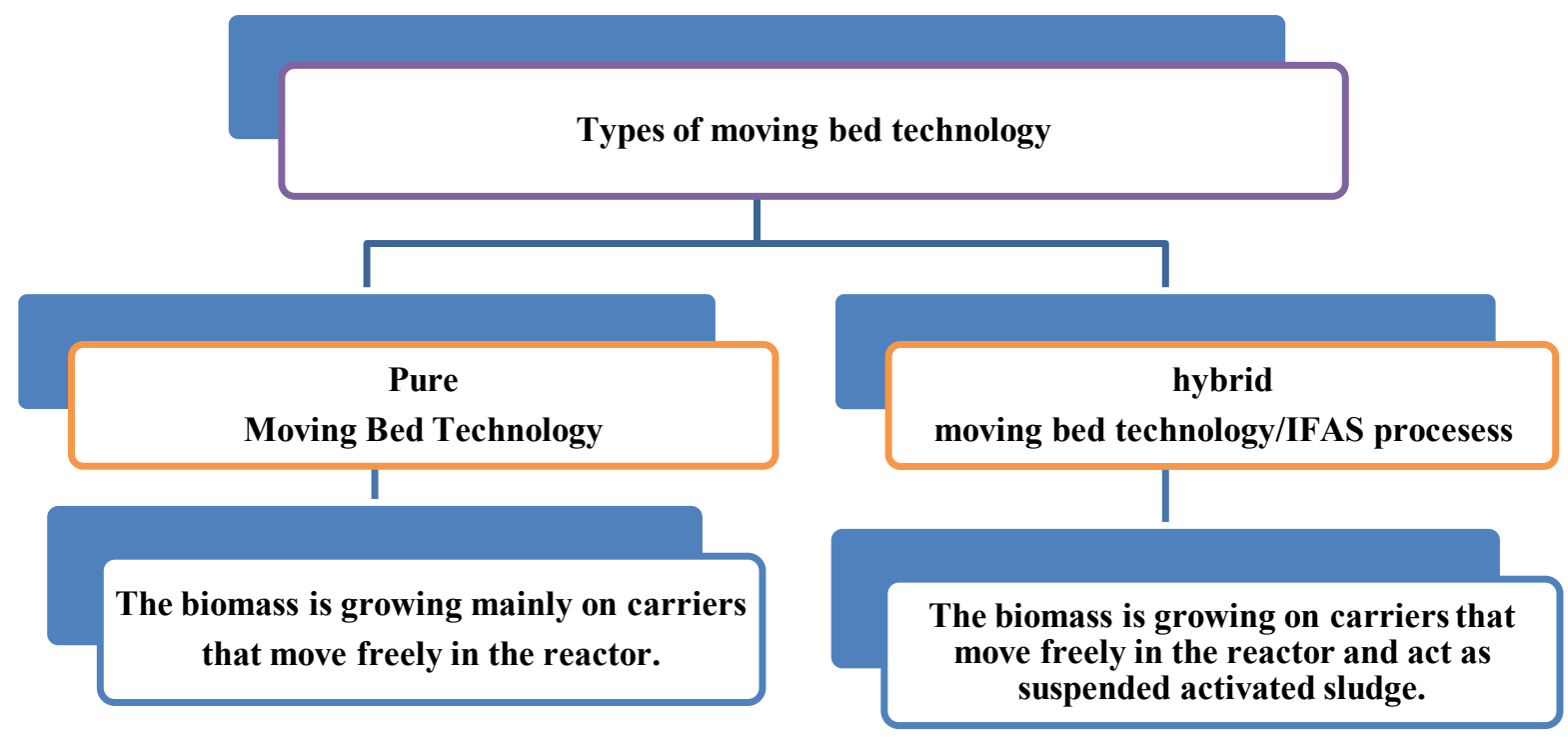

Researchers have proven that MBBR possesses have many excellent traits such as high biomass, high COD loading, strong tolerance to loading impact, relatively smaller reactor and no sludge bulking problem. There are presently more than 400 large-scale wastewater treatment plants based on this process in operation in 22 different countries all over the world. During the past decade it has been successfully used for the treatment of many industrial effluents including pulp and paper industry waste, poultry processing wastewater, cheese factory wastes, refinery and slaughter house waste, phenolic wastewater, dairy wastewater and municipal wastewater.

Recently, Moving Bed Biofilm Reactor (MBBR) has brought increasing research interest in practice for removal of biodegradable organic matter and its application has undergone various degrees of modification and development. Moreover, as the carrier using in the MBBR is playing a crucial role in system performance, choosing the most efficient carrier could enhance the MBBR performance. Hence, scientists have been looking for an appropriate carrier which is not costly and has a suitable surface for microbial growth. The main aim of this study is to evaluate a specific MBBR with polyethylene media as Biofilm support carrier in terms of OMs removal along with nutrient removal and microbial growth and activity.

\section{Advantage of Moving Bed Biofilm Processes}

The MBBR is a complete mix, continuous flow through process which combines the advantage of fixed film and suspended growth processes, this advantage include

1. Compact units with small size.

2. Increased treatment capacity.

3. Complete solids removal.

4. Improved settling characteristics.

5. Operation at higher suspended biomass

6. Concentrations resulting in long sludge retention times.

7. Enhanced process stability.

8. Low head loss.

9. No filter channeling.

10. No need of periodic backwashing.

11. Reduced sludge production and no problems with

12. Sludge bulking. 


\section{Review Of The Related Literature}

The Moving Bed Bio film Reactor (MBBR) represents a different spectrum in advanced wastewater treatment. In the late 1900s, Moving Bed Bio film Reactor (MBBR) was introduced for biological treatment of different types of wastewater.

Odegaard et al. (1994) stated that the Moving Bed Bio film Reactor (MBBR) process was developed in Norway during the late 1980 and early 1990. He concluded that the Moving Bed Bio film Reactor (MBBR) represented a different spectrum in advanced wastewater treatment. MBBRs were operated similarly to the activated sludge process with the addition of freely moving carrier media. According to Odegaard $\boldsymbol{e t}$ al. (2000), the fundamental characteristic of the MBBR was the specially designed Biofilm carriers, for which the geometry, sizing and materials of construction had been considered carefully to maximize performance. This was a key difference from the activated sludge process where treatment performance was more directly tied to reactor volume. In the MBBR, surface area could be increased by designing carriers with a higher specific surface area or by adding a greater quantity of carriers to a reactor volume. This offered flexibility for future treatment capacity upgrades without requiring the construction of additional reactors.

Bengoa Gorka Zalakain showed several advantages of Moving Bed Biofilm reactor from the operational point of view for small community compared to other conventional biological treatments. Processes studied had taken into account of Moving Bed Biological Reactors $\left(\mathrm{MBBR}^{\mathrm{TM}}\right)$ and hybrid processes (Hybas $\left.{ }^{\mathrm{TM}}\right)$.

Ødegaard and Rusten (1995) gathered data from various small full-scale wastewater treatment plants and the Moving Bed Biofilm Reactor systems started to develop. However, later, organic matter removal MBBR treatment systems were developed. Currently, MBBR systems are used as stand-alone treatment solutions and in tandem with other treatment processes including AS and membrane bioreactors for high strength organic wastewaters MBBR processes.

Brinkley John investigated processes that would treat variable high strength wastewater in a small footprint and provided provisions for future expansion. He selected the MBBR process due to the success the process had for treating high strength wastewater for comparable pharmaceutical applications. The 0.5 million gallon per day (mgd) MBBR process consisted of two reactors operated in series designed to treat an influent and effluent Biochemical Oxygen Demand (BOD5) of 3,197 mg/L and less than $75 \mathrm{mg} / \mathrm{L}$, respectively.

Maurer M. et al., (2001) performed detailed investigation on denitrification in a full-scale installation and a pilot plant for moving-bed biological treatment (MBBT). Two different types of carriers were used in conventional activated sludge reactors: foam cubes and plastic tubes (Kaldnes $\left.{ }^{\circledR}\right)$. Both investigated carriers showed the same behavior with regard to denitrification capacity, temperature dependency and maximum COD and nitrate turnover. In contrast to the plastic tubes (Kaldnes $\left.{ }^{\circledR}\right)$, the sponge cubes stored remarkable amounts of substrate. The maximum denitrification rate with acetate as a substrate was $420 \mathrm{~g} \mathrm{Nm}^{-3} \mathrm{~d}^{-1}$ at $10^{\circ} \mathrm{C}$ and $730 \mathrm{~g}$ $\mathrm{Nm}^{-3} \mathrm{~d}^{-1}$ at $20^{\circ} \mathrm{C}$. An average denitrification rate of $240 \mathrm{~g} \mathrm{Nm}^{-3} \mathrm{~d}^{-1}\left(10^{\circ} \mathrm{C}\right)$ was achieved with wastewater. A maximum of $37 \%$ of the COD in the influent was denitrified with a volumetric loading rate in the anoxic zone of $2.2 \mathrm{~kg} \mathrm{COD} \mathrm{m}^{-3} \mathrm{~d}^{-1 .}$

Karamany Hesham (2001) built a laboratory model simulating both suspended growth biological reactor and attached growth biological reactor in order to investigate the performance of the combined reactor. The RBC with fill and draw cups simulated the attached growth reactor, while the diffused air simulated the suspended growth reactor. He investigated the rate of oxygen transfer for four different configurations, three of them were tested using tab water and the fourth set of experiment was made using primary treated wastewater. First configuration investigated the oxygen transfer rate while the rotating disks operate alone. The second configuration investigated the oxygen transfer rate while the diffused air are in operation alone, and the third configuration investigated the oxygen transfer rate while both of the rotating disks and the diffused air are in operation together. The forth configuration investigated the oxygen transfer rate while both of the rotating disks and the diffused air are in operation together, but using primary treated wastewater sample instead of the tab water that had been used for the first three sets of experiments. Within the combined reactor the study showed better oxygen transfer rate can be get from the rotating biological contactor fill and draw rather than that of the diffused air system.

Borghei et al., (2004) used Moving Bed Biofilm Reactors in treating different domestic and industrial wastewaters. Currently, there are more than 400 units of full scaled wastewater treatment plants based on this process.

Åhl et al., (2006) explained that the aeration system also supplied sufficient oxygen so that at least the outer layers of the bio films were aerobic and thus were capable of proving relatively rapid biodegradation. The bio films grew and partially eventually detached from the carrier and the detached segments were carried by the liquid into the secondary clarifier for separation. The biologically-produced solid production by this system was 10 times less than that of the AS systems.

Odegaard, (2006) operated MBBRs similarly to the activated sludge process with the addition of freely moving carrier media. 
Kermani M., et al (2008) conducted the study to evaluate the organics, phosphorus and nutrients removal from synthetic wastewater by a laboratory scale moving bed biofilm process. For nutrients removal, moving bed biofilm process had been applied in series with anaerobic, anoxic and aerobic units in four separate reactors. Moving bed biofilm reactors were operated continuously at different loading rates of nitrogen and Phosphorus.

Delnavaz et al., (2008) suggested that MBBR is a suitable alternative for common activated sludge reactors in treating domestic and industrial wastewaters in commercial scale. Three moving bed biofilm reactors were used to treat synthetic wastewater of aromatic amine compounds. The reactors with cylindrical shape had an internal diameter and an effective depth of 10 and $60 \mathrm{~cm}$ respectively. The reactors were filled with light expanded clay aggregate as carriers and operated in an aerobic batch and continuous conditions. Evaluation of reactor's efficiency was done at different retention time of $8,24,48,72$ hours with an influent COD from 100 to $3500 \mathrm{mg} / \mathrm{L}$. the filling ratio was $50 \%$. The maximum obtained removal efficiency was $90 \%$ (influent COD $=750 \mathrm{mg} / \mathrm{L}$ ), $87 \%$ (influent $\mathrm{COD}=1000 \mathrm{mg} / \mathrm{L}$ ), $75 \%$ (influent $\mathrm{COD}=750 \mathrm{mg} / \mathrm{L}$ ).

Aygun Ahmet et al., (2008) studied moving bed biofilm reactor (MBBR), where biomass was attached to small carrier elements which were moving freely along with the water in the reactor, and tested it for organic matter removal at five different organic loading rates. A lab-scale reactor with a volume of $2 \mathrm{~L}$ was built and fed continuously with synthetic wastewater. The reactor was filled with the Kaldnes biomedia K1 which was used in the patented Kaldnes Moving Bed biofilm process at $50 \%$ of the volume of empty reactor. Hydraulic retention times (HRT) in the reactor and in the settler were adjusted to between 8 and 4 hours, respectively. A start-up period of about 4 weeks for biofilm growth on the carrier was followed by 10 weeks of testing period. By changing the wastewater composition, the operation of the system was adjusted, one after the other, to five different organic loading rates: $6,12,24,48$ and $96 \mathrm{~g} \mathrm{COD} / \mathrm{m}^{2} . \mathrm{d}$. Organic removal efficiency decreased with increasing organic loading rate, ranging from $95.1 \%, 94.9 \%, 89.3 \%, 68.7 \%$ and $45.2 \%$ as the organic loading rate was increased from 6 to $96 \mathrm{~g} \mathrm{COD} / \mathrm{m}^{2} . d$.

Kermani M., Bina B., et al (2009) conducted an experimental study to evaluate biological nitrogen and phosphorus removal from synthetic wastewater by a lab scale moving bed biofilm process. Also, kinetic analysis of the process with regard to phosphorus and nitrogen removal was studied with different mathematical models. For nutrient removal, the moving bed biofilm process was applied in series with anaerobic, anoxic and aerobic units in four separate reactors that were operated continuously at different loading rates of phosphorus and nitrogen and different hydraulic retention times.

Sombatsompop et al., (2011) aimed to comparatively study the efficiency of piggery wastewater treatment by the moving-bed sequencing batch reactor (moving-bed SBR) system with held medium, and the conventional sequencing batch reactor (SBR) system, by varying the organic load from 0.59 to $2.36 \mathrm{~kg}$ $\mathrm{COD} / \mathrm{m} 3$.d. The COD treatment efficiency of the SBR and moving-bed SBR was higher than $60 \%$ at an organic load of $0.59 \mathrm{~kg} \mathrm{COD} / \mathrm{m} 3 . \mathrm{d}$ and higher than $80 \%$ at the organic loads of $1.18-2.36 \mathrm{~kg} \mathrm{COD} / \mathrm{m} 3$.d. When the organic load was increased, the moving-bed SBR system yielded better treatment efficiency than that of the SBR system.

Yang Qiqi, et al, (2012) proved Moving Bed Biofilm Reactor (MBBR) technology as an alternative and successful method to treat different kinds of effluents under different conditions. Because there was a need to investigate how the bio solids dynamics were influenced by process changes relevant to applied wastewater treatment systems and suggested new routes to reactor design and optimization, the biofilm growth, detachment and modeling of MBBR were continue to draw significant research attention.

Mahmoudkhani Rouhallah et al, (2012) made the study which aimed at treatment of waters around Tehran Refinery contaminated with petroleum compounds. During study period a laboratory scale with a total liquid volume of $550 \mathrm{~L}$ was used. The reactor was filled with $85 \%$ Polyurethane elements, occupying $3 \%$ of the reactor's liquid volume. Pilot conditions were as follows, Temperature $=15$ to $25^{\circ} \mathrm{C}, \mathrm{pH}=6.7$ to 7.5 , dissolved oxygen $=4$ to $5 \mathrm{mg} / \mathrm{lit}$, MLSS $=1400$ to $1700 \mathrm{mg} / \mathrm{L}$ Hydraulic Retention Time $(\mathrm{HRT})=240$ minutes and unlimited Solid Retention Time (SRT), after suspended oil removal by oil separation system, COD, NO3-N and PO4-P removal efficiencies for the MBBR, filtration and activated carbon was 99,94 and $58 \%$, respectively. The results of the average effluent from each reactor showed that denitrification process in the preceding the aerobic MBBR, filtration and activated carbon occurred and in pre-denitrification system in filtration, consumed most of the biodegradable organic matter. In case of formaldehyde, phenol and total petroleum hydrocarbon (TPH) parameters, they were removed in the pilot up to 96,79 and $94 \%$, respectively.

Javid, A.H., et al, (2013) investigated feasibility of upgrading and retrofitting municipal wastewater treatment plants at laboratory scale using Moving Bed Biofilm Reactor (MBBR) process. For this purpose, an aerobic pilot was operated for nearly one year in different conditions, in which a moving bed carrier with a specific biofilm surface area of $500 \mathrm{~m} 2 / \mathrm{m} 3$ and a filling rate of $60 \%$ was utilized. System efficiency in removal of BOD5 and COD was examined at different hydraulic retention times (HRTs) of 1, 1.5, 2, 2.5, 3 and $4 \mathrm{~h}$. The obtained results indicated high ability of the system to tolerate organic loading and to remain stable at a high food to microorganism $(\mathrm{F} / \mathrm{M})$ ratio. The system produced effluents with good quality at low HRTs and led to an average 
BOD5 removal efficiency of nearly $88 \%$ during the operational period. The Organic Loading Rate (OLR) applied to the system had a range of $0.73-3.48 \mathrm{kgBOD} 5 / \mathrm{m} 3$.day and 2.43-11.6 gBOD5 $/ \mathrm{m} 2$.day, at which the reactor showed a good performance and stability.

After thorough evaluation of the related literature, it can be revealed that most of the work on Moving Bed biofilm reactors was carried out by using specially made Biomedia carriers. Certain experiments are done on Moving Bed Biofilm Reactors by taking nanofibres, diatomous earth, Biochips, porous material as media. It has also shown some positive results. But very rare work has been done by taking the stone bed in aeration tank. Literatures regarding the use of Stone bed as a media during the treatment processes are available in very less amount. Also very less information is available about the study carried out to access the performance of reactors fitted with different categories of aerators in combination, effect of change of flow regime on process performance, effect of air/ oxygen introduction in the system though different aerators. Hence the study is required to be undertaken to analyze the overall performance of Moving Bed Biofilm Reactors under such variable conditions by taking different combinations, trials and errors.

\section{Experimental set-up:}

\section{Materials And Methods}

The Moving Bed Biofilm Reactor (MBBR) technology is an attached growth biological treatment process based on a continuously operating, non-clogging biofilm reactor with low head loss, a high specific Biofilm surface area, and no requirement for backwashing. MBBR is often designed as aerobic system. Samples will be collected from low income and high income society and its parameters will be evaluated prior to treatment.

The proposed experimental set-up for Moving Bed Biofilm Reactor can be made as shown in Fig. 1.

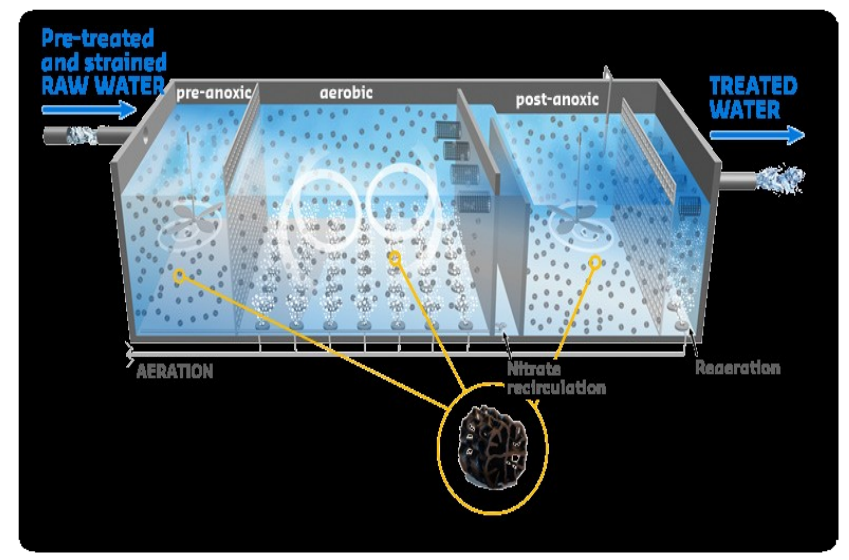

(Fig 1- Moving Bed Bilfilm Reactor experimental setup)

The Moving Bed Bioreactor (MBBR) setup proposed for this study will be made up of glass containing three compartments. The inlet arrangement for influent pre-treated raw domestic waste water will be given at the top of tank. The Outlet will be provided at lower level than inlet. The proposed experimental set-up for Moving Bed Biofilm Reactor can be made as shown in above Fig. 1

The Moving Bed Bioreactor (MBBR) process uses floating plastic carriers (media) within the aeration tank to increase the amount of microorganisms available to treat the wastewater compared to conventional secondary treatment. The microorganisms consume organic material. The media provides increased surface area for the biological microorganisms to attach to and grow in the aeration tanks. The increased surface area reduces the footprint of the tanks required to treat the wastewater. The media will be continuously agitated by bubbles from the aeration system that adds oxygen at the bottom of the first compartment of the aeration tank. The microorganisms consume organic material. The middle compartment will contain a channel of stones. The bottom portion of channel will contain large sized stones and upper channel will be of small sized stones. The waste water will be filtered through stone bed to some extent. After filtering, it will enter to last compartment through the openings provided in the setup. In last portion of tank where the bio carriers will be filled, turbulence will be provided to waste water with the help of rotors. After treatment, final treated effluent will be taken outside through outlet 


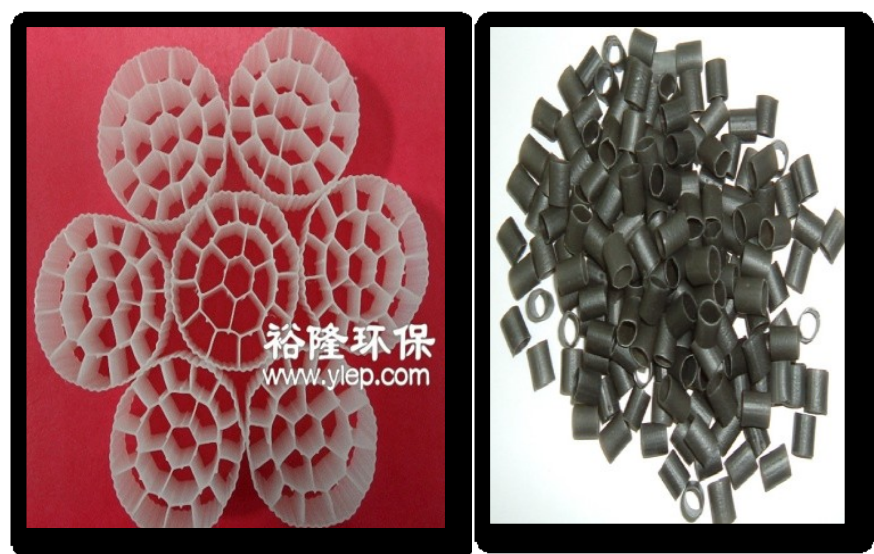

Table 1: Characteristics of the biomedia

\begin{tabular}{|l|l|}
\hline Material & $\begin{array}{l}\text { Polypropylene, plastic, ceramic, } \\
\text { porous }\end{array}$ \\
\hline Shape & $\begin{array}{l}\text { Corrugated cylinder, chips, hollow, } \\
\text { curved }\end{array}$ \\
\hline Density & $0.95 \mathrm{~g} \mathrm{~cm}^{-3}$ \\
\hline Dimensions & $10 \times 15 \mathrm{~mm}^{-3}$ \\
\hline Specific surface & $260 \mathrm{~m}^{2} \mathrm{~m}^{-3}$ \\
\hline
\end{tabular}

\section{Operating Principle}

The MBBR is a complete mix, continuous flow through process which is based on the biofilms principle that combines the benefits of both the activated sludge process and conventional fixed film systems without their disadvantages. The basic principal of the moving bed process is the growth of the biomass on plastic supports that move in the biological reactor via agitation generated by aeration systems (aerobic reactors) or by mechanical systems (in anoxic or anaerobic reactors).

The moving bed processes come from the current trend in wastewater treatment, from the use of systems that offer an increased specific surface in the reactor for the growth of the biomass, achieving significant reductions in the biological reactor volume. Reactor can be operated at very high load and the process is insensitive to load variations and other disturbances.

\section{Expected Result}

Today the need for clean water is rapidly increasing. So MBBR is technology becoming increasingly popular and widely used in the world to treating different kinds of effluents under different conditions because the idea of the MBBR is to combine the two different processes (attached and suspended biomass). This study may be helpful to check possibility that the moving bed biofilm process can used as an ideal and efficient option for the total nutrient removal from municipal wastewater. The mode of change of aeration provided during the experimental work may affect the efficiency of waste water treatment to good extent.

The Moving Bed technology may help to check the feasibility of waste water treatment by using both attached growth system and suspended growth system. This technology may be conducted to get low concentration of solids leaving the biological reactors, the absence of filamentous bulking and good settling characteristics of the sludge. The change in the type of media carriers during the experimental work may help to get the expected results in a very beneficial manner.

\section{References}

[1]. Ahl., R.M., Leiknes., T. \& Odegaard., H. (2006), “ Tracking particle size distributions in a moving bed biofilm membrane reactor for treatment of municipal wastewater.", Water Sci. Technol., 53: 33-42.

[2]. Andreottola., G., Foladori., P., \& Ragazzi., M. (2000), "Upgrading of a small wastewater treatment plant in a cold climate region using a moving bed biofilm reactor (MBBR) system", Water Sci.Technol. 41, 177-185.

[3]. Aygun Ahmet, et al., (2008) "Influence of High Organic Loading Rates on COD Removal and Sludge Production in Moving Bed Biofilm Reactor", Environmental Engineering Science, Volume 25, Number 9, 2008

[4]. Bengoa Gorka Zalakain, Moving Bed Technology for Small Communities.

[5]. Brinkley John, "moving bed bio film reactor technology - a full-scale installation for treatment of pharmaceutical wastewater."

[6]. Delnavaz., M., et al (2008), "Biodegradation of aromatic amine compounds using moving bed biofilm reactors." Iran. J. Environ. Health. Sci. and Eng., 5: 243-250.

[7]. Hosseini., K.E., et al. (2011), "Comparison of overall performance between moving-bed and conventional sequencing batch reactor." Iran. J. Environ. Health. Sci. Eng., 2011, Vol. 8, No. 3, pp. 235-244

[8]. Hem., L. J., Rusten., B., \& Odegaard., H. (1994), “Nitrification in a Moving Bed Biofilm Reactor”, Water Research, $28,1425$. 
[9]. Javid, A.H., et al.,(2013), "Feasibility of Utilizing Moving Bed Biofilm Reactor to Upgrade and Retrofit Municipal Wastewater Treatment Plants", Int. J. Environ. Res., 7(4):963-972,Autumn 2013

[10]. Karamany Hesham (2001) "Combined Suspended/Attached Growth Reactor : Oxygen Transfer Rate" Sixth International Water Technology Conference, IWTC 2001, Alexandria, Egypt

[11]. Kermani M., Bina B., et al (2008), "Application of moving bed biofilm process for biological organics and nutrients removal from municipal wastewater," American Journal of Environmental Sciences 4 (6): 675-682, 2008.

[12]. Kermani., M., Bina., B., et al (2009), "Biological phosphorus and nitrogen removal from wastewater using moving bed biofilm process," Iranian Journal Of Biotechnology, Vol. 7, No. 1, January 2009.

[13]. Kim B. K., et al (2011), "Wastewater Treatment in Moving-Bed Biofilm Reactor operated by Flow Reversal Intermittent Aeration System", World Academy of Science, Engineering and Technology 602011

[14]. Kriklavova Lucie (2010), "The Use of Nanofiber Carriers in Biofilm Reactor for the Treatment of Industrial Wastewaters", 12. - 14. 10. 2010, Olomouc, Česká Republika

[15]. Mahmoudkhani Rouhallah et al (2012), "Treatment of Contaminated Waters with Petroleum by Moving Bed Biofilm Reactor (MBBR)", International Conference on Life Science and Engineering, 10.7763/IPCBEE. 2012. V45. 3

[16]. Makowska M., et al., (2009), "Treatment of Septic Tank Effluent in Moving Bed Biological Reactors with Intermittent Aeration", Polish J. of Environ. Stud. Vol. 18, No. 6 (2009), 1051-1057

[17]. Marques J. J., et al., (2008), “Attached Biomass Growth and Substrate Utilization Rate in a Moving Bed Biofilm Reactor”, Brazilian Journal of Chemical Engineering, Vol. 25, No. 04, pp. 665 - 670, October - December, 2008

[18]. Maurer M., et al (2001), "Moving-bed biological treatment (MBBT) of municipal wastewater: denitrification", Water Science and Technology Vol 43 No 11 pp 337-344

[19]. Metcalf and Eddy, Inc., (2003), "Wastewater Engineering: Treatment, Disposal and Resue," 4th Ed.; Tchobanoglous, G., Burton, F.L., and Stensel, D.H..; McGraw-Hill: New York,

[20]. Ødegaard., H., Rusten., B., \& Westrum., T. (1994) “A New Moving Bed Biofilm Reactor Applications and Results," Water Science and Technology, 29, 157-165.

[21]. Ødegaard., H. (2000) “Advanced Compact Wastewater Treatment Based On Coagulation And Moving Bed Biofilm Process," Water Science and Technology, 42(12): 33-48.

[22]. Rusten., B., Matteson., E., et al (1994), "Treatment of pulp and paper industry wastewater in novel moving bed biofilm reactors." Water Sci. Technol., 30: 161-171.

[23]. Rusten., B., Hem., L.J., Ødegaard., H. (1995), "Nitrification of municipal wastewater in moving-bed biofilm reactors." Water Environmental Research, 67(1), 75-86.

[24]. Rusten., B., et al (2006), "Design and operations of the Kaldnes moving bed bio film reactors." Aquacult Eng., 34: 322-331.

[25]. Sombatsompop Kwannate, et al., (2011), "A comparative study of sequencing batch reactor and moving bed sequencing batch reactor for piggery wastewater treatment", Maejo Int. J. Sci. Technol. 2011, 5(02), 191-203

[26]. Yang., Qiqi., Qiang., He., \& et al (2012), "Review on Moving Bed Biofilm Processes," Pakistan Journal of Nutrition 11 (9): 706-713, 2012

[27]. Yang., K., Dougherty., M., Yang., Li. (2009), "Municipal wastewater treatment through an aerobic bio film SBR integrated with a submerged filtration bed." Water Sci. Technol., 59: 917-926.

[28]. Yeon H. J., et al., (2011), "Comparison of Attached Growth Process with Suspended Growth Process”, World Academy of Science, Engineering and Technology 602011.

[29]. Zafarzadeh A, et al (2010) "performance of moving bed biofilm reactors for biological nitrogen compounds removal from wastewater by partial nitrification-denitrification process" Iran. J. Environ. Health. Science. Eng., 2010, Vol. 7, No. 4, pp. 353-364. 